\title{
Importance of latent heat release in ascending air streams for atmospheric blocking
}

\section{Journal Article}

Author(s):

Pfahl, Stephan; Schwierz, Cornelia; Croci-Maspoli, Mischa; Grams, Christian M.; Wernli, Heini (D)

Publication date:

2015-08-01

Permanent link:

https://doi.org/10.3929/ethz-a-010690671

Rights / license:

In Copyright - Non-Commercial Use Permitted

Originally published in:

Nature Geoscience 8, https://doi.org/10.1038/NGEO2487 
Final author version of the publication

Pfahl, S., Schwierz, C., Croci-Maspoli, M., Grams, C. M., and Wernli, H. Importance of latent heat release in ascending air streams for atmospheric blocking. Nature Geosci. 8, 610-614, doi:10.1038/ngeo2487 (2015)

Published article available at:

http://www.nature.com/ngeo/journal/v8/n8/full/ngeo2487.html 


\section{Importance of latent heat release in ascending air streams for atmospheric blocking}

S. Pfahl ${ }^{1}$, C. Schwierz ${ }^{2}$, M. Croci-Maspoli ${ }^{3}$, C. M. Grams ${ }^{1}$, and H. Wernli ${ }^{1}$

${ }^{1}$ Institute for Atmospheric and Climate Science, ETH Zurich

${ }^{2}$ Statistik Stadt Zürich

${ }^{3}$ Federal Office of Meteorology and Climatology MeteoSwiss, Zürich

Correspondence to:

Stephan Pfahl, Institute for Atmospheric and Climate Science, ETH Zurich,

Universitaetstrasse 16, 8092 Zurich, Switzerland

Email: stephan.pfahl@env.ethz.ch; phone: +41 4463293 65; fax: +41 446331058 
Atmospheric blocking is a key component of extratropical weather variability ${ }^{1}$ and can contribute to various types of extreme weather events ${ }^{2,3,4,5}$. Recent studies suggested that changes in blocking frequencies due to Arctic amplification and sea ice loss may enhance extreme events ${ }^{6,7}$, but the mechanisms potentially involved in such changes are still under discussion ${ }^{8,9,10,11}$. Current blocking theories are essentially based on dry dynamics and do not directly take moist processes into account $^{12,13,14,15,16,17}$. Here we use a 21-year climatology of blocking from reanalysis data and a Lagrangian approach to quantify the release of latent heat in clouds along the trajectories that enter the blocking. We show that $30-45 \%$ of the air masses involved in Northern Hemisphere blocking are heated by more than $2 \mathrm{~K}$ ( $>7 \mathrm{~K}$ in the median) in the 3 days prior to their arrival in the blocking anticyclone, and this number increases to $60-70 \%$ when considering a 7-day period. This reveals that, in addition to quasi-horizontal advection of air with low potential vorticity $^{12,13,14,15}$, ascent from lower levels associated with latent heating in clouds is of first-order importance for the formation and maintenance of blocking. This process should be accounted for when pondering about future changes in atmospheric blocking.

Atmospheric blocking refers to the formation of large-amplitude synoptic-scale quasistationary anticyclones in the extratropics, which typically extend vertically over the entire troposphere. Blocking influences local weather conditions and particularly the formation of extreme weather events in various ways: In summer over the continents between $50-70^{\circ} \mathrm{N}$, blocking favours co-located warm temperature extremes mainly due to adiabatic warming in the regionally confined circulation and clear-sky radiative 
heating ${ }^{4}$. In winter, blocking can be important for the equatorward advection of polar air masses downstream and the subsequent occurrence of cold spells ${ }^{2,3}$. Dipolar configurations of blocking and surface cyclones are often associated with near-surface wind extremes ${ }^{5}$, and blocking can act as a precursor to heavy precipitation events downstream ${ }^{2}$. However, potential future changes of the frequency and location of blocking and related weather extremes are still largely uncertain ${ }^{8,9,10}$. Furthermore, climate models typically exhibit biases in the representation of blocking ${ }^{18}$ and weather prediction models sometimes fail in accurately forecasting blocking onset, maintenance or decay ${ }^{19}$. It is thus essential to better understand and quantify the mechanisms leading to blocking formation.

A variety of theories have been proposed that describe different mechanisms involved in blocking dynamics, but a complete theory of the blocking life cycle is still missing (see the overview in ref. 17). Planetary-scale theories focus on large-scale waves and their interaction with the topography. Local theories emphasize the role of wave breaking ${ }^{16}$ and the isentropic advection of air with low potential vorticity (PV) into the blocking region ${ }^{12,13,14,15}$. All these theories are essentially based on dry atmospheric dynamics, and diabatic processes have only been considered in an indirect way, e.g., via the triggering of Rossby waves by tropical convection ${ }^{13}$. There are only few studies pointing to direct diabatic effects on blocking: Tilly et al. ${ }^{20}$ investigated two events in the Southern Hemisphere and found substantial diabatic contributions to blocking intensification, whereas Cheung et al. ${ }^{21}$ found diabatic effects to be of secondary importance for blocking formation over Siberia. Backward trajectory calculations from North Atlantic blockings during selected winters presented in refs. 22 and 23 indicate 
that latent heating is often involved in the upward transport of air with low PV into the upper-tropospheric blocking. In this study, again a combined PV and Lagrangian approach is used to systematically assess the relevance of this diabatic mechanism for Northern Hemisphere blocking based on 21 years of ERA-Interim reanalysis data.

Different indices have been developed to identify blocking based on geopotential height, potential temperature ( $\theta$ ) or PV (see the methodological discussion in ref. 18). Here the approach of ref. 24 is applied, which identifies blocking as regions with anomalously low vertically integrated PV in the middle to upper troposphere that are quasi-stationary and exist for at least 5 days $^{24,25,4}$ (see methods). This PV-based definition enables us to objectively identify air masses in the upper troposphere that are involved in blocking. Kinematic backward trajectories using three-dimensional reanalysis winds ${ }^{26}$ are calculated to reconstruct the history of these air masses and determine the sources of the low PV air. By tracing the evolution of $\theta$ and PV along more than $10^{8}$ trajectories during the 21 years, we can discriminate between adiabatic PV advection (as described in the classical blocking theories ${ }^{12,13,14,15}$ ) and crossisentropic transport due to in-cloud latent heating, and climatologically assess the frequency of the two mechanisms. The robustness of our results with respect to the blocking identification is evaluated through comparison with a more classical blocking index based on geopotential height ${ }^{27}$.

The PV-based index identifies blocking mainly over the North Pacific $\left(40-60^{\circ} \mathrm{N}\right)$ and North Atlantic $\left(50-70^{\circ} \mathrm{N}\right)$ in all seasons and over the Arctic in $\operatorname{summer}^{4}$ (Fig. S1). By design of the PV-based index, all blocking trajectories are characterized by negative PV 
anomalies (calculated as the deviation of the trajectory's PV from the seasonal climatology at the same location) at day 0 , i.e., at the time of arrival in the blocking region (black line in Fig. S2). For the geopotential height index, the PV anomaly distribution at day 0 is very similar (dashed line in Fig. S2), corroborating that the two indices identify dynamically comparable features. The key question now is how these PV anomalies have been created and whether their creation involved significant diabatic heating. Figure 1a shows, for all blocking trajectories, the joint frequency distribution of the PV anomaly at the location of the trajectory at day -3 , i.e., 3 days prior to arriving in the blocking, and the diabatic heating during this 3-day period. The diabatic heating is calculated as the difference between the $\theta$-maximum and previous $\theta$-minimum along the trajectory (see methods). This distribution clearly reveals two contrasting regimes of air parcels contributing to blocking: a quasi-adiabatic regime with almost no latent heating but a wide range of PV anomaly values at day -3 (between -3 and $+1 \mathrm{pvu}$ ), and a diabatic regime with a strong increase of $\theta$ and fairly small PV anomaly values at day -3 (mainly within $\pm 0.5 \mathrm{pvu}$ ). A threshold of $\Delta \theta=2 \mathrm{~K}$ is used to separate these regimes (dashed vertical line, Fig. 1a). The no-heating regime comprises $54 \%$ of the blocking air masses, while $46 \%$ experience a heating of more than $2 \mathrm{~K}$ (category C, Fig. 1a). Trajectories in the no-heating regime are further classified according to the sign of their PV anomaly at day $-3: 44 \%$ of all trajectories are associated with a negative PV anomaly (category B) and 10\% with a positive PV anomaly (category A). If PV anomalies and maximum diabatic heating are evaluated along the 7-day backward trajectories, diabatic processes are even more important (Fig. 1b). On this time scale, $69 \%$ of the blocking air masses experience latent heating $\Delta \theta>2 \mathrm{~K}$. The contributions of the different categories do not vary substantially between different seasons (Fig. S3). 
When using the geopotential height index ${ }^{27}$ to identify blocking, the number of diabatic trajectories is slightly lower on a 3 -day time scale (32\%), but more comparable for -7 days (61\%), which can be explained by the typical spatial configuration of PV and geopotential height anomalies (see Fig. S4 and discussion in Methods section).

Interestingly, the number of air parcels affected by diabatic heating varies with blocking age (Fig. 2): Diabatic processes are more important during blocking onset than in the later maintenance phase. The percentage of category $\mathrm{C}$ trajectories (with $\Delta \theta>2 \mathrm{~K}$ in 3 days) is $59 \%$ for the first 2 days of the blocking lifecycle and decreases to $42 \%$ for blocks older than 4 days (Figs. 2 and S6). Anticyclonic anomalies with a lifetime shorter than 5 days are substantially less influenced by diabatic processes (dashed line, Fig. 2).

To obtain a more detailed picture of the differences between air parcels in the 3 categories defined above, Fig. 3 shows statistical results for the trajectories in all seasons, and Fig. 4 the spatial distributions of these trajectories at day -3 separately for summer and winter. By construction, trajectories from categories A and B experience almost no heating, but show distinct variations of PV and the PV anomaly at day -3 (Fig. 3a-d; the median temporal evolution is shown in Fig. S7). The more frequent category B trajectories are characterized by low PV and negative PV anomalies already at day -3 , and weak material PV changes during transport (Fig. 3d). This category corresponds to the mechanism proposed in ref. 15 , according to which the blocking anomaly is maintained by selectively absorbing other synoptic-scale anticyclones. The trajectories exhibit only weak vertical and a comparatively small meridional 
displacement (Fig. 3e,f). Three days before arrival (day -3), they are already located close to the main blocking regions (Fig. 4c,d; distributions at day -1.5 and day 0 shown in Figs. S8 and S9, respectively). A striking feature of category B is the asymmetric geographical distribution with a higher frequency in the North Atlantic compared to the North Pacific (Fig. S9). For category A, the positive PV anomalies at day -3 correspond also to comparatively high PV values ( $>1$ pvu in about $20 \%$ of the cases), which are reduced during transport to the blocking anticyclone (Fig. 3c,d), probably due to radiative processes and turbulent mixing with air from lower levels. However, in most cases the absolute PV values at day -3 are not particularly high. They correspond to weakly positive anomalies at lower latitudes (cf. Fig. 4a,b), but are transformed into negative anomalies due to the relatively large poleward transport to regions where climatological PV is higher ${ }^{13}$ (Fig. 3f).

For category $\mathrm{C}$, the median diabatic heating along the 3-day (7-day) trajectories is $8.5 \mathrm{~K}$ $(12.5 \mathrm{~K})$ and it reaches values of more than $25 \mathrm{~K}$ in 3 days (Fig. 3a). A median heating of $7.2 \mathrm{~K}$ in 3 days is found for the geopotential height blocking index. The large meridional displacement and ascent of the diabatic category $\mathrm{C}$ trajectories (Fig. 3e,f) indicate a pronounced cross-isentropic flow of air from lower latitudes and altitudes into the blocking anticyclones. In winter, the trajectories originate mainly from the western parts of the North Atlantic and North Pacific storm tracks (Fig. 4e). Origins over land are much more abundant in summer (Fig 4f). This difference is consistent with the seasonality of surface evaporation and thus moisture availability. The cloud and precipitation formation during the ascent of these air parcels and the associated latent heat release enable the marked cross-isentropic flow. These cloud- 
diabatic processes also modify PV, but the PV increase in the beginning of the ascent is typically compensated by subsequent PV destruction ${ }^{26,28,29}$, resulting in net crossisentropic transport of low-PV air. Such moist, slantwise ascending air streams commonly occur in connection with extratropical cyclones and are denoted as warm conveyor belts (WCBs) $)^{26,28,29}$. The position of the blocking trajectories at day -3 in winter (Fig. 4e) is in good agreement with the climatological distribution of WCB starting points ${ }^{28}$, although only $5 \%$ of the blocking trajectories ascend more than 600 $\mathrm{hPa}$, which is used as a criterion for the identification of WCBs in this climatology. During summer, the frequency of WCBs is greatly reduced ${ }^{28}$, in agreement with the typically weaker ascent of the blocking trajectories (Fig. S10).

In conclusion, our climatological Lagrangian analysis reveals the existence of two mechanisms associated with the occurrence of atmospheric blocking in the Northern Hemisphere, and quantitatively shows that they are similarly important. In agreement with classical blocking theories ${ }^{12,13,14,15}$, quasi-adiabatic flow contributes to blocking through the isentropic advection of air masses with mainly low PV. Of equal importance is the diabatic input of low PV entering the blocking region via ascending air streams fuelled by the release of latent heat during cloud formation. The climatologically robust identification of the first-order importance of this diabatic mechanism is a novel finding. It indicates that systematic problems in blocking forecasts $^{19}$, similar to errors in the structure of Rossby waves ${ }^{30}$, may be due to an erroneous representation of latent heating in weather prediction models. Furthermore, it suggests that, in addition to changes in horizontal temperature gradients ${ }^{7,10}$, Rossby wave dynamics ${ }^{11}$ and sea ice cover ${ }^{6}$, the enhanced atmospheric moisture content and its 
effect on latent heating must be considered when pondering about future changes of atmospheric blocking.

\section{References}

1. Rex, D. Blocking action in the middle troposphere and its effect on regional climate. I: An aerological study of blocking. Tellus 2, 169-211 (1950).

2. Carrera, M. L., Higgins, R. W. \& Kousky, V. E. Downstream weather impacts associated with atmospheric blocking over the Northeast Pacific. J. Climate 17, 4823-4839 (2004).

3. Sillmann, J. \& Croci-Maspoli, M. Present and future atmospheric blocking and its impact on European mean and extreme climate. Geophys. Res. Lett. 36, L10702 (2009).

4. Pfahl, S. \& Wernli, H. Quantifying the relevance of atmospheric blocking for co- located temperature extremes in the Northern Hemisphere on (sub-)daily time scales. Geophys. Res. Lett. 39, L12807 (2012).

5. Pfahl, S. Characterising the relationship between weather extremes in Europe and synoptic circulation features. Nat. Hazards Earth Syst. Sci. 14, 1461-1475 (2014).

6. Liu, J., Curry, J. A. Wang, H., Song M. \& Horton, R. M. Impact of declining Arctic sea ice on winter snowfall. Proc. Natl. Acad. Sci. U.S.A. 109, 4074-4079 (2012).

7. Francis, J. A. \& Vavrus, S. J. Evidence linking Arctic amplification to extreme weather in mid-latitudes. Geophys. Res. Lett. 39, L06801 (2012). 
8. Screen, J. A. \& Simmonds I. Exploring links between Arctic amplification and mid-latitude weather. Geophys. Res. Lett. 40, 959-964 (2013).

9. Barnes, E. A., Dunn-Sigouin, E., Masato, G. \& Woolings, T. Exploring recent trends in Northern Hemisphere blocking. Geophys. Res. Lett. 41, 638-644 (2014).

10. Hassanzadeh, P., Kuang, Z. \& Farrell, B. F. Responses of midlatitude blocks and wave amplitude to changes in the meridional temperature gradient in an idealized dry GCM. Geophys. Res. Lett. 41, 5223-5232 (2014).

11. Coumou, D., Petoukhov, V., Rahmstorf, S., Petri, S. \& Schellnhuber, H. J. Quasi-resonant circulation regimes and hemispheric synchronization of extreme weather in boreal summer. Proc. Natl. Acad. Sci. U.S.A., doi:10.1073/pnas.1412797111(2014).

12. Shutts, G. J. The propagation of eddies in diffluent jetstreams: eddy vorticity forcing of 'blocking' flow fields. Q. J. R. Meteorol. Soc. 109, 737-761 (1983).

13. Hoskins, B. J. \& Sardeshmukh, P. D. A diagnostic study of the dynamics of the northern hemisphere winter of 1985-86. Q. J. R. Meteorol. Soc. 113, 759-778 (1987).

14. Nakamura, H., Nakamura, M. \& Anderson, J. L. The role of high- and lowfrequency dynamics in blocking formation. Mon. Weather Rev. 125, 2074-2093 (1997).

15. Yamazaki, A. \& Itoh, H. Vortex-vortex interactions for the maintenance of blocking. Part I: the selective absorption mechanism and a case study. J. Atmos. Sci. 70, 725-742 (2013). 
16. Masato, G., Hoskins, B. J. \& Woolings, T. J. Wave-breaking characteristics of midlatitude blocking. Q. J. R. Meteorol. Soc. 138, 1285-1296 (2012).

17. Tyrlis, E. \& Hoskins, B. J. Aspects of a Northern Hemisphere atmospheric blocking climatology. J. Atmos. Sci. 65, 1638-1652 (2008).

18. Barnes, E. A., Slingo, J. \& Woolings, T. A methodology for the comparison of blocking climatologies across indices, models and climate scenarios. Clim. Dyn. 38, 2467-2481 (2012).

19. Ferranti, L., Corti, S. \& Janousek, M. Flow-dependent verification of the ECMWF ensemble over the Euro-Atlantic sector. Q. J. R. Meteorol. Soc., doi:10.1002/qj.2411, in press (2014).

20. Tilly, D. E., Lupo, A. R., Melick, C. J. \& Market, P. S. Calculated height tendencies in two Southern Hemisphere blocking and cyclone events: The contribution of diabatic heating to block intensification. Mon. Weather Rev. 136, $3568-3578$ (2008).

21. Cheung, H. N. et al. Observational climatology and characteristics of wintertime atmospheric blocking over Ural-Siberia. Clim. Dyn. 41, 63-79 (2013).

22. Schwierz, C. Interactions of Greenland-scale orography and extratropical synoptic-scale flow, Ph.D. thesis, 155 pp., ETH Zurich, Switzerland (2001).

23. Croci-Maspoli, M. \& Davies, H. C. Key dynamical features of the 2005/06 European winter. Mon. Weather Rev. 137, 664-678 (2009).

24. Schwierz, C., Croci-Maspoli, M. \& Davies, H. C. Perspicacious indicators of atmospheric blocking. Geophys. Res. Lett. 31, L06125 (2004).

25. Croci-Maspoli, M., Schwierz, C. \& Davies, H. C. A multifaceted climatology of atmospheric blocking and its recent linear trend. J. Climate 20, 633-649 (2007). 
26. Wernli, H. \& Davies, H. C. A Lagrangian-based analysis of extratropical cyclones. I: The method and some applications. Q. J. R. Meteorol. Soc. 123, 467489 (1997).

27. Scherrer, S. C., Croci-Maspoli, M., Schwierz, C. \& Appenzeller, C. Twodimensional indices of atmospheric blocking and their statistical relationship with winter climate patterns in the Euro-Atlantic region. Int. J. Climatol. 26, 233-249 (2006).

28. Madonna, E., Wernli, H., Joos, H. \& Martius, O. Warm conveyor belts in the ERA-Interim data set (1979-2010). Part I: Climatology and potential vorticity evolution. J. Climate 27, 3-26 (2014).

29. Methven, J. Potential vorticity in warm conveyor belt outflow. Q. J. R. Meteorol. Soc., doi:10.1002/qj.2393, in press (2014).

30. Gray, S. L., Dunning, C. M., Methven, J., Masato, G. \& Chagnon, J. M. Systematic model forecast errors in Rossby wave structure. Geophys. Res. Lett. 41, 2979-2987 (2014).

\section{Acknowledgements}

We thank MeteoSwiss for providing access to ECMWF analysis data. Discussions with Huw Davies have been very helpful for designing this study. Comments from two anonymous reviewers helped us to improve the manuscript. C.M.G. acknowledges support from the Swiss National Science Foundation (Grant PZ00P2_148177 / 1). 


\section{Author contribution}

All authors designed the study and discussed the results and manuscript. S.P. analysed the data, S.P. and H.W. wrote the manuscript.

\section{Additional information}

The authors declare no competing financial interests. Supplementary online material accompanies this paper. Correspondence and requests for materials should be addressed to S.P.

Figures
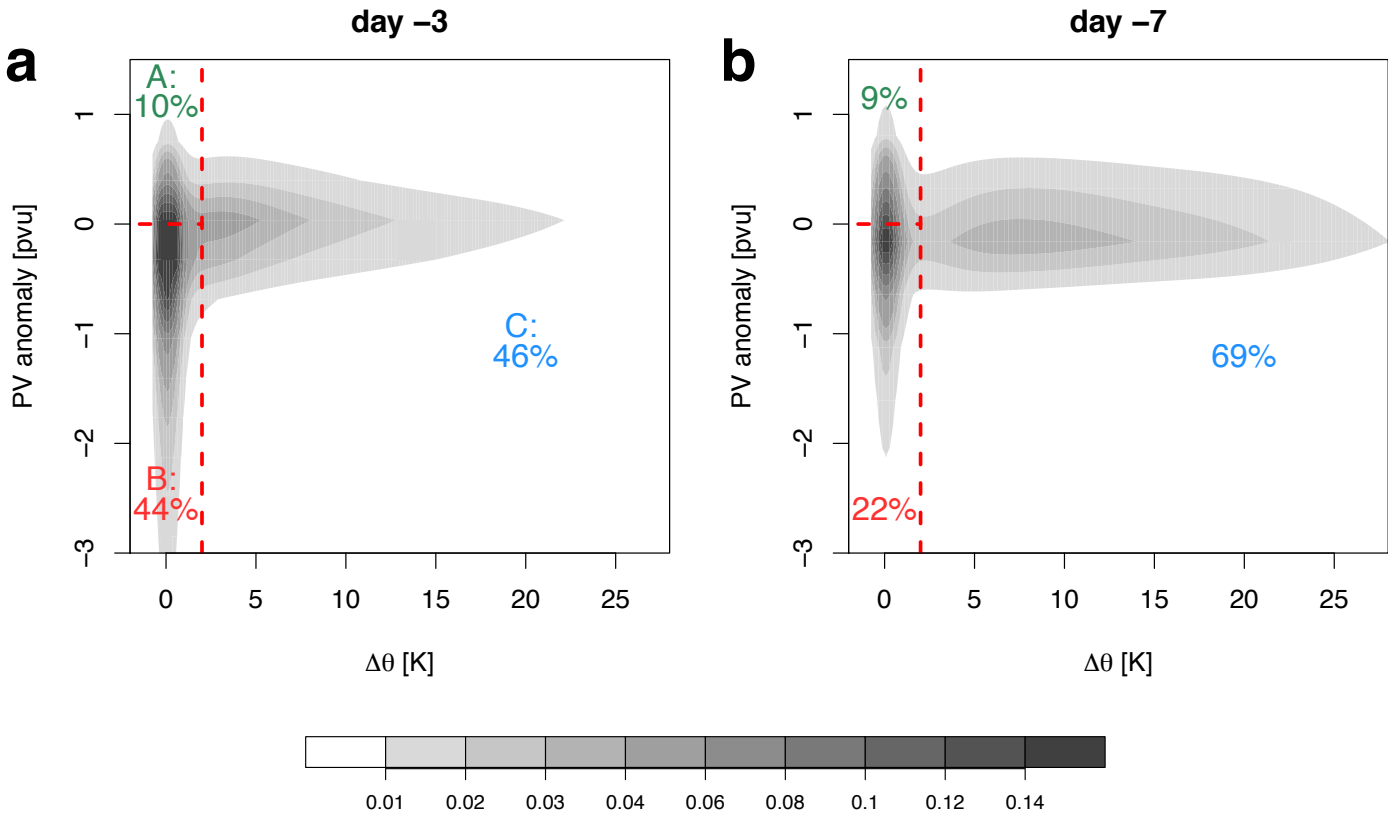

Figure 1. Diabatic heating and PV anomalies along trajectories computed

backward from the blocking region. Two-dimensional joint frequency distributions of PV anomalies at the location of the backward trajectories (a) 3 days and (b) 7 days prior to their arrival in the blocking region and maximum diabatic heating along the 
trajectories during this period. Grey shading shows frequency densities as obtained from a non-parametric fit using Gaussian kernels. Percentages of blocking air parcels in the 3 categories defined by the red dashed lines (and labelled A, B, C in panel a) are given in colour.

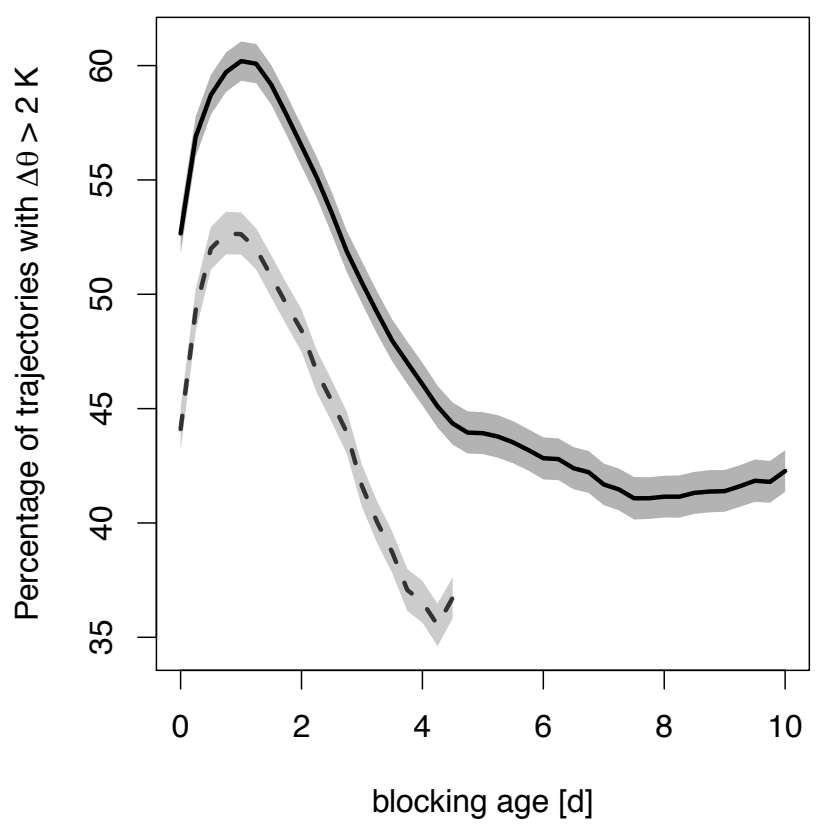

Figure 2. Diabatic heating during blocking lifecycle. Percentage of 3-day backward trajectories affected by diabatic heating (category $\mathrm{C}$ in Fig. 1a) as a function of blocking age (solid line). The latter is defined as the number of days since the first identification of a specific blocking anomaly. The dashed line shows the percentage of trajectories affected by diabatic heating for anticyclonic anomalies that persist less than 5 days and are thus not classified as blocking. The grey shading indicates $90 \%$ confidence intervals estimated with the help of a resampling approach $\left(10^{4}\right.$ random samples of $10^{4}$ trajectories each for every age category). 

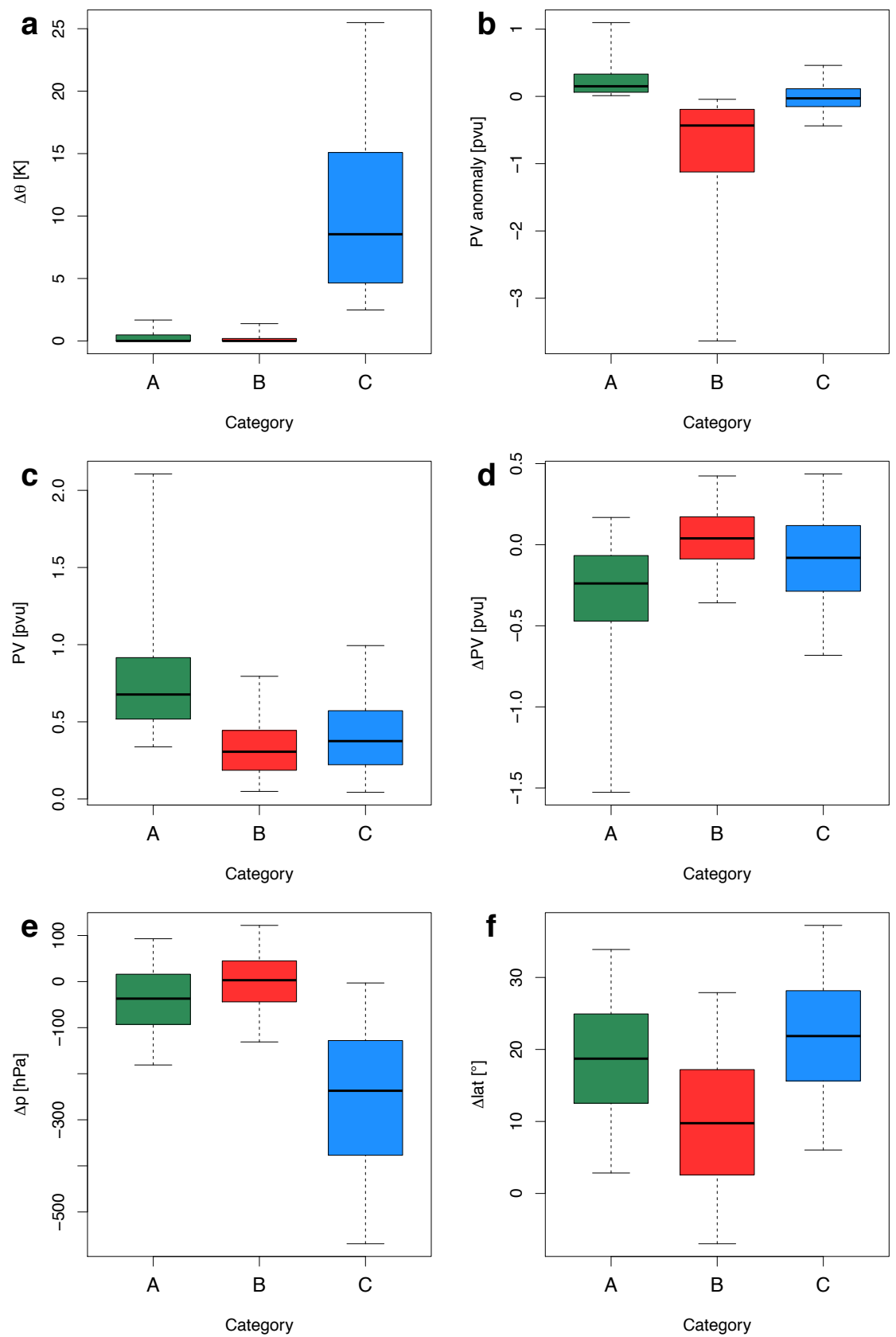

Figure 3. Properties of blocking trajectories. Statistical distributions of (a) maximum diabatic heating, (b) PV anomaly, (c) PV, (d) PV change, (e) maximum ascent, and (f) latitudinal displacement along 3-day backward trajectories from blocking regions for the 3 categories defined in Fig. 1a. Horizontal lines show the medians, boxes the interquartile ranges and whiskers the 5 th and 95 th percentiles. 

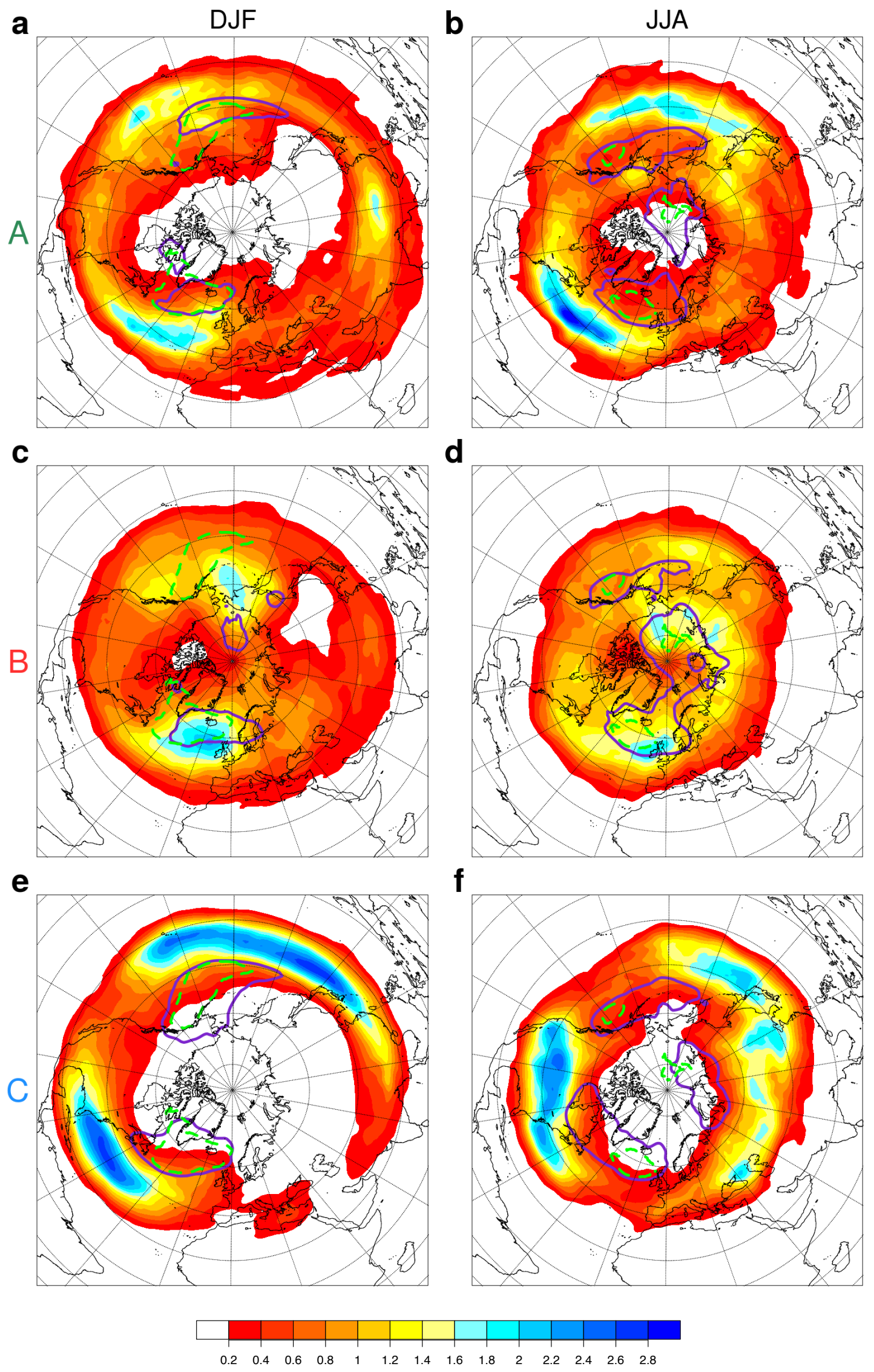
Figure 4. Spatial distributions of blocking trajectories. Colour shading shows spatial densities of air parcels 3 days prior to arriving in a blocking region for the 3 categories defined in Fig. 1a (a,b: category A; c,d: category B; e,f: category C) and for the winter (December-February, left column) and summer season (June-August, right column). Units are $\%\left(10^{6} \mathrm{~km}\right)^{-1}$ and are normalized such that the spatial integral over each distribution yields 1 . The purple contours indicate the main backward trajectory starting locations (density contour value of 2; see Fig. S9). Regions where the total blocking frequency is larger than $7 \%$ are shown by the dashed green contour.

\section{Methods}

Blocking identification. Data are obtained from the ERA-Interim reanalysis of the European Centre for Medium-Range Weather Forecasts ${ }^{31}$ for the period 1989-2009 on a $1^{\circ} \times 1^{\circ}$ longitude-latitude grid in the Northern Hemisphere. The atmospheric blocking data set of ref. 4 is used. It is based on the algorithm of ref. 24, which defines blocking as temporally persistent regions with low vertically integrated PV between 500 and 150 $\mathrm{hPa}$. To be identified as blocking, the vertically integrated PV must be 1.3 pvu lower than the monthly climatology in the same region during at least 5 days (denoted as intense blocking in ref. 4). The climatological blocking frequencies in summer and winter are shown in Fig. 2 of ref. 4 and Fig. S1; they attain maximum values of $10 \%$ in the North Atlantic and eastern North Pacific. The advantage of the PV index is that, in contrast to other indices, it directly identifies blocking air masses in a dynamically consistent way, as shown in many case studies ${ }^{24,25}$, and thus directly allows investigating their origin and characteristics. To test the robustness with respect to the 
blocking identification method, a two-dimensional blocking index based on geopotential height gradients on the $500 \mathrm{hPa}$ surface is also used ${ }^{27}$, as explained in detail below.

Trajectory calculations. Three-dimensional kinematic 7-day backward trajectories are calculated from all grid points horizontally located in a blocking region at each sixhourly time step using the Lagrangian Analysis Tool ${ }^{26}$. In the vertical, backward trajectories are started at these horizontal grid points from pressure levels between 500 and $150 \mathrm{hPa}$ with a spacing of $50 \mathrm{hPa}$, with the additional criterion that PV must be smaller than $1 \mathrm{pvu}$ (to exclude points located in the stratosphere). Altogether, this yields more than 114 million trajectories in the 21-year period. Although they are started from a geographical grid, all statistical analyses presented are area-weighted, i.e., backward trajectories starting further poleward get less weight. Note that with our setup, an air mass that resides in the blocking for more than six hours is represented by several trajectories started at 6-hourly intervals. A major difference to previous studies based on isentropic trajectories ${ }^{15}$ is that here the full three-dimensional wind field is used, thus allowing for the quantification of Lagrangian changes of potential temperature (similar to ref. 23). In addition to the air parcel location, various quantities are tracked along the trajectories: potential temperature $(\theta), \mathrm{PV}$, the PV anomaly (with respect to the local seasonal climatology), and material changes of $\mathrm{PV}, \theta$ and pressure along the trajectories. Maximum latent heating $(\Delta \theta)$ is defined as the difference between the maximum value of $\theta$ and the preceding minimum value during a specific time period along the trajectories (analogously for maximum ascent considering the time evolution of pressure). They are calculated both for the 7 and 3 days prior to the start of the backward trajectory in the blocking region. If $\theta$ decreases or pressure decreases 
monotonically, the value is set to zero. Note that since we focus on the role of latent heating, this measure of $\Delta \theta$ does not account for diabatic cooling, e.g., due to clear-sky radiation. Indeed, many trajectories in the category $\Delta \theta<2 \mathrm{~K}$ experience radiative cooling of several degrees prior to arriving in the blocking region (not shown). The results do not change substantially if a different definition of maximum diabatic heating is applied, for instance if all positive six-hourly $\theta$ changes along a trajectory are summed up (Fig. S11). The trajectory model does not have a parameterization of moist convection and may thus underestimate direct convective contributions to blocking. Nevertheless, such contributions are assumed to be small, since deep convection is often suppressed by subsidence in blocking anticyclones.

Robustness with regard to the blocking identification. To test the robustness of our results with regard to the definition of atmospheric blocking, the trajectory approach is also applied to blocking features identified with a geopotential height-based blocking index ${ }^{27}$ (in addition to the PV index ${ }^{24}$ used for the main climatological analysis). This absolute geopotential height (AGP) index is a two-dimensional extension of the classical Tibaldi-Molteni-index ${ }^{32}$, which is also based on geopotential height, with some small modifications as explained in ref. 27. The AGP index is used here to identify blocking in a latitude band between $45^{\circ}$ and $75^{\circ} \mathrm{N}$. Note that the lower latitudes included in ref. 27 are excluded here to avoid the identification of subtropical highs, which are different dynamical features and therefore intentionally not captured by the PV approach. With the AGP index, a grid point is considered as blocked if, during a period of 5 days or more, the geopotential height gradient is larger than 0 in the southerly direction and smaller than $-10 \mathrm{~m}$ per degree latitude in the northerly direction $^{32}$ (with both gradients calculated over a $15^{\circ}$ meridional segment). In 
agreement with the climatology of ref. 27, who used an earlier ECMWF reanalysis dataset, maxima of the AGP blocking frequency are found poleward and downstream of the PV blocking frequency maxima in the North Atlantic sector (Fig. S1). Over the North Pacific, AGP blocking is mostly detected in more poleward regions compared to PV blocking. Note that, although the AGP blocking definition does not explicitly take the PV distribution into account, PV anomalies associated with AGP blocking are nearly as pronounced as for the PV blocking index (Fig. S2).

The joint frequency distributions of PV anomalies and diabatic heating along the backward trajectories initialized in the AGP blocking regions (Fig. S4) have a similar shape as for the PV-based analysis (compare with Fig. 1). Also for the AGP blockings, a quasi-adiabatic and a diabatic regime can be clearly distinguished. At day -3 , the effect of diabatic heating integrated until day 0 is less pronounced for the AGP blockings than for the PV blockings, and the number of diabatic trajectories is smaller ( $32 \%$ for the AGP compared to $46 \%$ for the PV index). This difference is reduced on a 7-day time scale. If latent heating is integrated over 7 days then the maximum values of $\Delta \theta$ are comparable for the two blocking indices $(>25 \mathrm{~K})$ and the number of diabatic trajectories are more similar (61\% for the AGP vs. $69 \%$ for the PV index). To explain these differences between the two blocking indices, an example from a blocking period in January 2001 in the North Atlantic region is shown in Fig. S5. The AGP index identifies blocking over the British Isles and the North Sea (green contour), in the centre of a broad ridge indicated by the geopotential height field. A partly overlapping blocking region is identified by the PV index, which extends further to the north and northwest, i.e., in upstream direction, than the AGP block. On a 3-day time scale, diabatic heating mainly affects the westerly and northerly parts of the PV block (orange 
dots), which is not captured by the AGP index. The diabatically influenced air masses then re-circulate in the blocking region, such that on a 7-day time scale diabatic trajectories also reach more downstream areas (red dots) where also the AGP index detects the blocking (see again Fig. S1). This fairly typical example (see ref. 23 for a similar blocking case) indicates that (i) the two indices capture a comparable blocking feature but with a certain shift in space and time, and therefore (ii) the diabatic contribution to the blockings is very similar on a time scale of 7 days, but on shorter time scales this contribution is larger for PV blocks that are typically further upstream, i.e., closer to the region where the diabatic ascent occurs (which is similar for both blocking indices, cf. Figs. 4 and S12).

In summary, this analysis shows that diabatic heating also is of first-order importance when the blocking air masses are identified using the AGP index. The differences between the two blocking indices (mainly on a 3-day time scale) are, in a dynamically consistent way, related to the typically more downstream location of AGP blockings. This comparison thus strongly corroborates the robustness of our findings presented in the main part of the paper that are based on the PV blocking index.

Data and code availability. The ERA-Interim data can be obtained from the ECMWF data server (see https://software.ecmwf.int/wiki/display/WEBAPI/Access+ECMWF+Public+Datasets). The blocking identification code is available from https://svn.iac.ethz.ch/websvn/pub; the trajectory code can be accessed at http:/www.iac.ethz.ch/staff/sprenger/lagranto/. 


\section{Additional references for methods section}

31. Dee, D. P. et al. The ERA-Interim reanalysis: configuration and performance of the data assimilation system. Q. J. R. Meteorol. Soc. 137, 553-597 (2011).

32. Tibaldi, S. \& Molteni, F. On the operational predictability of blocking. Tellus $A$ 42, 343-365 (1990). 